\title{
FEMINISMO, GÊNERO E POLÍTICAS PÚBLICAS: desafios para fortalecer a luta pela emancipação
}

\author{
Lourdes de Maria Leitão Nunes Rocha \\ Universidade Federal do Maranhão (UFMA)
}

FEMINISMO, GÊNERO E POLÍTICAS PÚBLICAS: desafios para fortalecer a luta pela emancipação

Resumo: O presente ensaio tece considerações sobre o feminismo na contemporaneidade, destacando a implementação de políticas públicas para as mulheres na perspectiva de gênero e de fortalecimento da luta pela emancipação humana. Apresentam-se aspectos da discussão sobre o feminismo em suas variadas expressões, explicitando concepções orientadoras e reflexões relativas à atual fase do movimento feminista. Busca-se resgatar elementos do debate sobre as tendências epistemológicas e teórico-metodológicas, bem como, da atuação e lutas do movimento feminista e seus fundamentos. A partir do entendimento das políticas públicas como processo histórico, social e político, destaca-se o papel relevante desse movimento como sujeito na formulação e execução das políticas públicas para as mulheres. Aborda-se, brevemente, a constituição dos organismos executivos, a realização das conferências e elaboração da política e dos planos de políticas para as mulheres no Brasil, questionando-os e indagando sobre lutas e construção de estratégias na direção da emancipação feminina e humana.

Palavras-chave: Feminismo, gênero, políticas públicas para as mulheres, emancipação.

FEMINISM, GENDER AND PUBLIC POLICIES: challenges to strengthen the fight for emancipation

Abstract: The present study talks about contemporary feminism and the implementation of public policies for women on gender perspective and strengthening of the struggle for human emancipation. It presents aspects of discussion on feminism in its various expressions, making explicit guidelines conceptions and reflections concerning the current phase of the feminist movement. It aims to rescue elements of the debate on the epistemological and methodological-theoretical trends, as well as the performance and struggles of the feminist movement and its fundamentals. From the understanding of public policies as historical, social and political process, it detaches the relevant role of that movement as a subject in the formulation and implementation of public policies for women. It is briefly discussed the establishment of executive organisms, the implementation of the conferences and the preparation of policy and political plans for women in Brazil, questioning them and asking about fights and building strategies towards the female and human emancipation.

Key words: Feminism, gender, public policies for women, emancipation. 


\section{INTRODUÇÃo}

A primeira condição para modificar a realidade consiste em conhecê-la. (Eduardo Galeano).

A proposição da mesa temática Movimento de Mulheres e feministas: experiências e antecipações concretas na VII Jornada Internacional de Políticas Públicas oportuniza a reflexão coletiva sobre alguns dos desafios e inquietações do tempo presente. Indiscutivelmente, as reivindicações por direitos, equidade e igualdade, bem como pela implementação de políticas públicas, a relação com o Estado e os governos são exemplos de questões surgidas nas lutas feministas desde o final dos anos 1970. Portanto, a minha participação nesta mesa é difícil tarefa, na medida em que devo trazer para debate os vínculos, ou sua ausência, entre políticas públicas, feminismo, a perspectiva de gênero e a luta pela emancipação.

O desafio cresce diante da conjuntura nacional extremamente desfavorável para a garantia das conquistas já efetivadas e para o reconhecimento de novos direitos. Falo do avanço do neoconservadorismo, dos fundamentalismos e do acirramento de preconceitos, discriminações e violência contra segmentos ditos minoritários da população brasileira. Quadro agravado pela crise global que atinge as economias capitalistas e não é mais simplesmente uma marola no Brasil.

Nos limites desta comunicação, não pretendo aprofundar conceitos e nem adentrar nas polêmicas produzidas pelas diferentes perspectivas teóricas e políticas existentes no âmbito acadêmico e dos movimentos sociais e feministas. Diante da complexidade do tema e das inúmeras vias de compreensão e atuação, elegi alguns pontos para suscitar a discussão.

Assim, reconhecendo a importância da temática, proponho-me, inicialmente, apresentar alguns aspectos do debate sobre o feminismo em suas variadas expressões. Em segundo lugar, faço uma abordagem breve sobreas políticas para as mulheres no Brasil e os desafios na luta pela emancipação.

Não há certezas, pois me deparei com muitas interrogações e a convicção da permanente necessidade de estudar, pesquisar e militar.

2 FEMINISMO(S): breves considerações e provocações

Não importa de onde vim, mais sim aonde quero chegar. (Eduardo Galeano).

Ao principiar as considerações sobre o tema em comento, julgo necessário explicitar concepções que as orientam e ousar inserir no debate formulações em construção sobre a atual fase do movimento feminista. São brevíssimas e iniciais reflexões, pois nos limites deste texto de torna impossível apontar e aprofundar o conjunto das questões teóricas e políticas que perpassam e fundamentam a produção do conhecimento e a prática do feminismo.

Compartilhando com o pensamento de várias autoras, entendo o feminismo (prefiro denominá-lo os feminismos), em sua diversidade de correntes e tendências, atuando em diferentes espaços e formas que não são estanques. Expresso neste primeiro momento a concepção majoritária do campo socialista feminista em que iniciei minha militância.

Considero-o movimento(s) social(is), que defende um projeto político e o desenvolve por meio de ação de natureza também política, envolvendo teoria e prática, alicerçada seticamente em valores e princípios (FERREIRA, 1999).

Percebo o feminismo como ideologia ou doutrina que "[...] preconiza a igualdade entre os sexos e a redefinição do papel da mulher na sociedade." (SARDENBERG; COSTA, 2002, p. 24). Dito de outro modo: defende a liberdade, a igualdade e combate a assimetria, a dominação e exploração nas relações de gênero, que atingem significativamente as mulheres em sua diversidade.

O feminismo se constitui também um campo epistemológico, teórico e metodológico, com diferentes tendências, em crítica ao campo científico, suas instituições e práticas de produção do conhecimento gendradas, desvantajosas para as mulheres e outras minorias.

Narvaz e Koller (2006) registram como principais linhas epistemológicas feministas o empiricismo feminista, a teoria do ponto de vista feminista (feministstandpointtheory), o construcionista social, o feminismo pós-moderno (pós-estruturalista e desconstrucionista) e a epistemologia feminista com base na física quântica e a pesquisa irônica (satiricalempiricism).

Carvalho (2012) identifica três abordagens: empirismo feminista, teoria do ponto de vista feminista e feminismo pós-modernista. Com base na Stanford Encyclopedia of Philosophy explica:

Empirismo feminista: busca padrões de diferenciação de circunstâncias nas quais a situação gera erros ou constitui um recurso para avançar o conhecimento, propondo uma concepção de objetividade constituída por relações críticas e cooperativas entre várias/os investigadoras/es diferencialmente situadas/os. [...] O empirismo feminista considera que a ciência não pode atingir conhecimento objetivo sobre seres gendrados ou sobre o mundo social gendrado sem incluir ativamente pesquisadoras feministas como iguais no projeto científico coletivo (Helen Longino). (CARVALHO, 2012, p. 7-9). 
Teoria do ponto de vista feminista (feministstandpointtheory): se insere no paradigma da Teoria Crítica ao identificar uma perspectiva social particular como epistemicamente privilegiada - a de grupos em desvantagem, oprimidos (ex: no marxismo, o ponto de vista do proletariado; a epistemologia feminista negra). Vale-se da consciência bifurcada, ser de fora e estar dentro, a habilidade de ver tanto da perspectiva do dominador quanto da perspectiva do oprimido (W.E.B. DuBois, Sandra Harding, Dorothy Smith, Patricia Hill Collins).

O estilo cognitivo feminino é considerado epistemicamente superior porque supera a dicotomia sujeitoobjeto e porque uma ética do cuidado é superior a uma ética de dominação. Assim, modos de conhecer motivados pelo cuidado da necessidade de todos produzirá representações mais valiosas do que modos de conhecer motivados pelo interesse de dominar, como propõe Nancy Hartsock; produzirão representações do mundo focadas em interesses humanos universais (e não nos interesses das classes dominantes). (CARVALHO, 2012, p. 4-5).

Feminismo pós-modernista: rejeita argumentos de privilégio epistêmico, enfatizando a contingência e instabilidade das identidades dos sujeitos cognoscentes e, portanto, suas representações.

Postulados: a realidade é discursivamente construída; ações e práticas são signos linguísticos, assim como o próprio self; as tensões entre identidades conflitantes possibilitam perturbar os sistemas discursivos que nos constroem. Se o mundo não dita as categorias que usamos para descrevêlo, há infinitas maneiras de descrevêlo e, portanto, a escolha de uma dada teoria não pode ser justificada pelo apelo à verdade ou realidade "objetiva". O feminismo pós-modernista contesta a ideologia sexista de uma natureza ou essência feminina, postulando que o gêneroé socialmente ou discursivamente construído (Maria Lugones, Elizabeth Spelman, Jane Flax, Judith Butler); oferece uma crítica interna ao conceito de "mulher" - feministas negras e lésbicas contestaram a legitimidade do ponto de vista de mulheres brancas, de classe média, heterossexuais; e propõe uma estratégia de mudança de perspectiva para negociar a proliferação de teorias produzidas por mulheres diversamente situadas. (CARVALHO, 2012, p. 5-6, grifos da autora).

Sem a pretensão de reforçar enquadramentos, percebo que os desafios da contemporaneidade nos convidam ao diálogo crítico com as vertentes, estabelecendo a interlocução plural nos aspectos em que se comunicam de fundamentar a crítica feminista da ciência e a ciência feminista.

Reitero a imbricação entre perspectivas epistêmico-teóricas do feminismo, ideologia e atuação política. Deste ponto de vista há que se ressaltar a relação com projetos societários direcionadores de outros movimentos, questão discutida por várias(os) autoras(os). Narvaz e Koller (2006, p. 649), fundamentadas em Chrisler e Smith (2004) e Toledo (2003), comentam que:

\begin{abstract}
As intersecções do feminismo com os movimentos de luta de classes configuram diferentes movimentos feministas, entre eles: o radical (inclui-se aqui o movimento de mulheres negras), o liberal, o socialista, o marxista e o anarquista.
\end{abstract}

Por sua vez, Saffioti (1987) construiu uma taxionomia dessas posições no Brasil que são reveladas nos tipos de abordagens sobre as mulheres: a liberal-burguesa, a feminista radical, a marxista dogmática e a socialista feminista.

Impõe-se nestas reflexões mencionar as mais recentes e instigantes reflexões e proposições de Marlise Matos: desde o inicio do milênio está em curso a quarta onda para o movimento feminista no Brasil e na América Latina, que constitui também a possibilidade da construção de uma proposta teórica no campo crítico-emancipatório das diferenças ${ }^{1}$ (MATOS, 2014; MATOS; BRENO CYPRIANO, 2008). Tais proposições são uma demonstração da vitalidade do feminismo, de sua importância, diversidade, e, por isso mesmo, de explicitação de polêmicas.

O cenário de emergência da denominada quarta onda é montado a partir de ocorrências econômicas, políticas e sociais ocorridas desde os anos 1990. Neste contexto, Matos (2014) menciona a mudança na relação dos feminismos com o Estado; a institucionalização e profissionalização do movimento e surgimento de novas formas de organização; as consequências da implementação das políticas neoliberais, dentre elas a responsabilização das ONGs feministas por politicas sociais, mesmo reconhecendo o avanço

[...] na introdução dos temas relativos ao gênero nas agendas nacional e internacional ao passo que relativizaram em parte sua função de criticar, pressionar e transformar esse mesmo Estado. (MATOS, 2014, p. 7).

Ressalta a autora algumas modificações na década 2000. Cita o decréscimo da tensão sobre a institucionalização dos feminismos (fragilização dos grupos autônomos e por parte das organizações institucionalizadas autocríticas de sua 
atuação). Refere-se ainda ao nascimento de outros movimentos:

Além disso, outros movimentos feministas emergiram pautados por forte crítica ao neoliberalismo, como a Marcha Mundial das Mulheres6, revigorando as pautas políticas dos feminismos na região e abrindo processos de aliança com outros movimentos sociais, a partir do resgate da ação feminista de rua, criativa e subversiva, no contexto de emergência dos movimentos antiglobalização e da construção do Fórum Social Mundial (FSM). Como afirmam Nobre e Trout (2008), o FSM transformou o ambiente do debate e ação políticas e trouxe uma oportunidade de articulação de ambos os "lados" dos feminismos. (MATOS, 2014, p. 7, grifo da autora).

Repercutiram nessa conjuntura os resultados negativos das políticas neoliberais e a reação dos movimentos sociais e partidos políticos progressistas fortalecidos eleitoralmente. Ambos alimentaram a possibilidade da construção de alternativas que aliassem crescimento econômico, democracia e justiça social. O foco mudou para o Estado, o acesso aos direitos e à cidadania, influindo nas relações entre o Estado e a sociedade civil, bem como, na abordagem do feminismo do e para com o Estado.

Mediante este contexto Matos (2014, p. 7 , grifo da autora) defende sua posição a respeito da quarta onda do feminismo:

O feminismo, em parte significativa dos países da região latino-americana na atualidade não só foi transversalizado - estendendo-se verticalmente (numa arranjo mainstreaming) por meio de diferentes níveis do governo, atravessando a maior parte do espectro político e engajando-se em uma variedade de arenas políticas aos níveis nacionais e internacionais -, mas também se estendeu horizontalmente, fluiu horizontalmente ao longo de uma larga gama de classes sociais, de outros movimentos que se mobilizavam pela livre expressão de experiências sexuais diversas e também no meio de comunidades étnico-raciais e rurais, bem como de múltiplos espaços sociais e culturais, inclusive em movimentos sociais paralelos. Essa conformação expressa aquilo que estamos definindo como "quarta" onda feminista.

Nos países do Sul global, onde se inclui o Brasil, essa recente configuração se revela tanto nos movimentos quanto nos estudos e teorias feministas. A difusão do feminismo (feministsidestreaming - fluxo horizontal do feminismo) realizada por diferentes correntes, a exemplo, da acadêmica, negra, lésbica, masculina, entre outras, e a entrada na agenda pública da maior representação política das mulheres são destacados por Matos (2014).

Ressalvo que, nesse período, passam a fazer parte do discurso, das reivindicações e ações do feminismo os conceitos: transversalidade de gênero (gendermainstreaming), transversalização, intersetorialidade, interseccionalidade. Tais conceitos se constituem, sobretudo, estratégias para a implementação de políticas públicas.

A ressalva acima ganha mais sentido ao expor as características da quarta onda arroladas por Matos (2014, p. 10-11, grifos da autora):

1. O alargamento, adensamento e aprofundamento da concepção de direitos humanos que tem sexo, gênero, cor, raça, sexualidade, idade, geração, classe social etc. (pautado a partir da luta feminista e das mulheres e de outros movimentos e muito diferente da proposta liberal, abstrata e transcendental de dignidade humana que orientou no começo a plataforma internacional vinculada a estes direitos); 2. A ampliação e diversificação da base das mobilizações sociais e políticas, sobretudo dentro de um novo enquadramento ou moldura transnacional, global, além de uma moldura resignificada nacionalmente ${ }^{2}$ [...]

3. O foco no "sidestreaming" feminista, ou seja, uma perspectiva que reforça a discriminação de gênero mas vai além dela e valoriza igualmente o princípio da não-discriminação com base na raça, etnia, geração, nacionalidade, classe ou religião. Trata-se do reconhecimento de "feminismos outros", profundamente entrelaçados, e, por vezes controversamente emaranhados com as lutas nacionais e globais para a justiça social, sexual, geracional e racial. [...]

4. O foco no "mainstreaming" feminista, onde ganham visibilidade e destaque as novas formas de relação com o Estado e de suas muitas instituições e àquelas dinâmicas vinculadas a este novo formato de teorização feminista, destacando-se, por sua vez, o esforço no sentido da construção participativa de ações transversais, interseccionais e intersetoriais de despatriarcalização das instituições estatais;

5. Também se destaca a nova forma teórica - transversal e interseccional - de compreensão dos fenômenos de raça, gênero, sexualidade, classe e geração desdobram-se na necessidade de se pensar em micro e macroestratégias de ação articuladas, integradas, construídas em conjunto pelo Estado e pela sociedade civil a partir de um novo feminismo interseccional, transversal, multinodal, policêntrico (estatal e anti-estatal ao mesmo tempo despatriarcalizador e descolonizador);

6. Uma renovada retomada e 
aproximação entre pensamento, a teoria e os movimentos feministas (o "campo crítico emancipatório das diferenças", Matos, 2013 [...] que se propõe a uma reformulação teórica profunda com forte concentração em tradições teóricocríticas feministas contemporâneas decoloniais e que visam um novo enquadramento para um feminismo cosmopolita.

O que importa para os fins deste texto não é a defesa de que adentramos na quarta onda feminista e opção por uma nova proposta teórica, mas resgatar elementos do intenso debate sobre as tendências epistemológicas e teóricometodológicas, bem como, da atuação e lutas dos movimentos feministas e seus fundamentos, para tecer considerações sobre as políticas públicas para as mulheres no Brasil, nos anos 2000.

\section{FEMINISMO(S), POLÍTICAS PARA AS MULHERES NO BRASIL E EMANCIPAÇÃO}

\begin{abstract}
A utopia está lá no horizonte. Me aproximo dois passos, ela se afasta dois passos. Caminho dez passos e o horizonte corre dez passos. Por mais que eu caminhe, jamais alcançarei. Para que serve a utopia? Serve para isso: para que eu não deixe de caminhar. (Eduardo Galeano).
\end{abstract}

A perspectiva norteadora das colocações que aqui serão expostas, parte do entendimento que as políticas públicas desenvolvidas em nosso país, nascem e são executadas em resposta às necessidades postas pelo desenvolvimento capitalista, em interseção com as relações de gênero, étnico-raciais e geracionais, expressando uma profunda contradição da regulação social: de um lado, "[...] é constituída por processos que geram desigualdade e exclusão.", numa sociedade que defende formalmente os princípios emancipadores da igualdade, da liberdade e da cidadania; de outro, "[...] estabelece mecanismos que permitem controlar ou manter dentro de certos limites esses processos." (SANTOS, 1999, p. 5).

Politicas Públicas se constituem maneiras de regulação ou de intervenção do Estado, através de um conjunto de ações ou omissões, na mediação de interesses e do poder de diferentes sujeitos, o que implica vontade política no sentido de distribuir ou não o poder e de estender os benefícios sociais. Trata-se de um processo social, histórico, inacabado, contraditório e complexo. Tal processo é composto de etapas, interdependentes e articuladas, distinguidas mais para efeito de compreensão e análise: transformação do problema em questão, formulação da agenda, formulação de alternativas de políticas, adoção da política, implementação (execução) e avaliação da política (SILVA, 2008).
É, por conseguinte, um processo político, no qual diferentes sujeitos negociam, estabelecem ou desfazem alianças e participam dele de modo e em momentos diferenciados. Destacam-se como sujeitos envolvidos em toda dinâmica de implementação das públicas: grupos de pressão, movimentos sociais e outras organizações da sociedade; partidos políticos ou políticos individualmente; administradores e burocratas; técnicos, planejadores e avaliadores; judiciário; meios de comunicação social, dentre outros (SILVA, 2008).

Diante do exposto, cumpre distinguir o importante papel dos movimentos de mulheres e movimentos feministas enquanto sujeitos das políticas públicas, que têm sido mencionados por vários(as) autores(as), a exemplo de Mészáros (2002), e Wallerstein (2003). Autores que ressaltam a ampliação dos movimentos e sua dimensão antisistêmica.

Demarco especialmente a análise de Mészáros (2002, p. 216) sobre a crise estrutural do modo capitalista de controle social ao explicitar uma de suas principais teses: a existência de limites intrínsecos ou absolutos do capital, que quando "[...] são alcançados no desenvolvimento histórico, é forçoso transformar os parâmetros estruturais da ordem estabelecida." Defende que mesmo com as resistências postas pelo capital, foram ativados esses limites, mantendo a crise estrutural iniciada na segunda metade do século passado.

O autor, ao discutir os quatro limites absolutos do capital ativados, ressalta entre eles: as questões colocadas pela exigência da liberação das mulheres, de sua emancipação, que se transformou em uma dificuldade não integrável ao capital, pois sua satisfação exige a garantia da igualdade substantiva, impossível de ser alcançada sob o sistema do capital (MÉSZÁROS, 2002). Com a derrocada do socialismo e o fortalecimento do discurso da sociedade sem classes e da palavra vazia da igualdade, o movimento de mulheres movimento de questão única, para ele - incorporou a luta pela emancipação dos seres humanos do domínio do capital. Enfatiza:

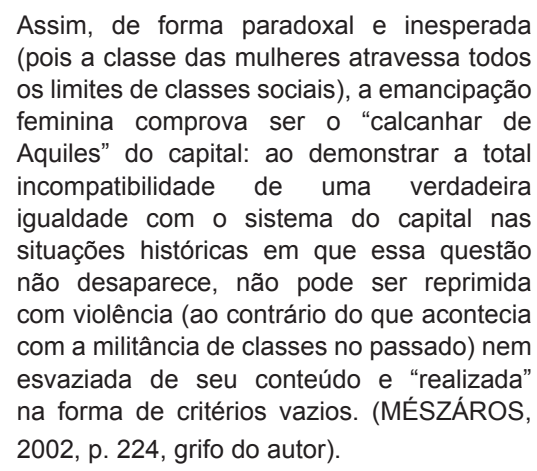

No contexto destas considerações, retorno 
à reflexão sobre o feminismo no Brasil e sua relevância como sujeito das políticas públicas para as mulheres nos marcos das denominadas segunda e terceira ondas (ou fases).

A partir do final dos anos 1970, forjado na resistência à ditadura militar e na luta pela democracia, o feminismo se fortaleceu, diversificou, questionou e ampliou a noção de política e suas práticas, levou para a arena pública questões então consideradas secundárias e pessoais (afetividade, sexualidade, violência, reprodução, poder, dupla jornada de trabalho e outras), desvelou a desigualdade das relações de gênero e exigiu respostas do Estado ás demandas historicamente invisibilizadas. Nesse processo distingue-se a luta pela ampliação da participação nos espaços de poder, representação e controle social (PINTO, 2003).

Algumas reivindicações são conquistadas e ecoarão no novo milênio nas lutas pela efetivação e permanências dos avanços, bem como para criação de novos direitos e políticas públicas. Para atender o escopo deste artigo detenho-me nos organismos de políticas para as mulheres, denominados por Matos (2014) de mecanismos institucionais de mulheres (MIMs), destacando sua atuação na realização das conferências e planos de políticas para as mulheres.

Conforme Matos (2014) este período caracteriza a quarta onda feminista (iniciada em 2000), em que a relação com o Estado se concretiza pela via da institucionalização estatal (feminismo estatal): MIMs e planos nacionais de políticas para as mulheres.

De forma diferenciada, Buarque (2006) afirma que, a partir dos anos de 1990, o feminismo entra no terceiro período: Feminismo de Governo: conquista dos espaços de decisão. A autora observa:

No Brasil especificamente, duas iniciativas do movimento feminista constituem-se em divisores de águas, entre a fase anterior e o período que se abre a partir dos anos de 1990, o qual estamos chamando de Feminismo de Governo: de um lado, as propostas de constituição de órgãos especializados para a promoção da eqüidade (sic) de gênero, com autonomia financeira no interior do aparelho de Estado; e de outro, a retomada de investimentos para a ampliação da participação das mulheres na democracia representativa, a exemplo das Políticas de Cotas, por sexo, para candidaturas ao Parlamento. [...] o Feminismo de Governo se caracteriza pela luta das mulheres para dividir com os homens os espaços de poder. Esse fenômeno se revela tanto pela busca feminista de criar estruturas e ocupar cargos dentro dessas estruturas, como, também, pela dependência que ainda tem a sobrevivência dessas estruturas e a indicação das mulheres para os seus cargos, de compromissos pontuais dos governantes, que, na sua maioria, é formada de homens que não reconhecem, como necessário à democracia, se constituir, na prática dos poderes, a igualdade entre homens e mulheres. (BUARQUE, 2006, p. 19).

Respaldando-me nos estudos e debates realizados pelo Grupo de Pesquisa e Extensão sobre Relações de Gênero, Étnico-Raciais, Geracional, Mulheres e Feminismos (GERAMUS), do qual sou integrante, e principalmente no posicionamento da professora Silvane Nascimento, questiono as terminologias feminismo de governo e feminismo estatal. Em respeito à luta feminista, brevemente apontada acima, opto por denominar feminismo no governo (ou será feminismo no Estado?)

As reivindicações de democracia participativa, consubstanciada na criação e participação em conselhos de políticas e de direitos, particularmente, os conselhos de direitos da mulher; de elaboração e alterações nas medidas legislativas e normas jurídicas; pela efetivação de serviços e mudanças na forma e qualidade do atendimento referentes às políticas de saúde, segurança, educação, trabalho, etc. constituíram/em bandeiras de luta levantadas pelo feminismo nos últimos 50 anos.

Entre as demandas e conquistas mais recentes inclui-se a criação de organismos executivos de políticas para as mulheres. Sob várias denominações e vinculações nas estruturas de governos municipais, estaduais e federal, essas novas institucionalidades convivem com os limites e obstáculos advindos do caráter classista, patriarcal, racista, homofóbico/lesbófico do estado e da sociedade brasileira. Em meio há muitos entraves, dificuldades estruturais e orçamentárias e tantas outras, não se pode desconsiderar que há avanços.

Nesse contexto, sobressai-se a criação em 2003, no governo Lula, da Secretaria Especial de Políticas para as Mulheres da Presidência da República (SPM) ${ }^{3}$, com status de Ministério. Assim como os organismos estaduais e municipais, sobretudo do primeiro escalão, a SPM trouxe modificações nas relações com demais órgãos governamentais e na dinâmica da formulação, coordenação, articulação e implementação de políticas para as mulheres.

O Decreto n. 8.030/2013, anexo I art. $1^{\circ}$, inciso III define como uma das suas competências o

$$
\begin{aligned}
& \text { [...] planejamento da incorporação da } \\
& \text { perspectiva de gênero na ação do Poder } \\
& \text { Executivo federal e demais esferas } \\
& \text { públicas, para a promoção da igualdade } \\
& \text { de gêneros. (BRASIL, 2013a). }
\end{aligned}
$$

Competência que remete a utilização das estratégias de transversalização de gênero horizontal e vertical, e inserção da intersetorialidade, interseccionalidade para a implementação 
das políticas públicas para as mulheres, como anteriormente comentado.

Pontuo nesse processo de construção a relevância das Conferências Municipais, Estaduais e Nacional de Políticas para as Mulheres (2004, 2007, 2011), da significativa participação dos movimentos de mulheres e feministas na preparação e realização desses eventos e de materialização nos Planos Nacionais (2004, 2008, 2013).

A I Conferência Nacional possui um simbolismo especial: a definição da Política Nacional para as Mulheres (natureza, princípios e diretrizes da Política Nacional na perspectiva da igualdade e equidade de gênero, considerando a diversidade de raça e etnia e livre orientação sexual), matriz para da elaboração do I Plano Nacional de Políticas para as Mulheres (I PNPM). Nas demais conferências os princípios e diretrizes foram reafirmados e os eixos, objetivos e ações avaliados, alterados e ampliados.

Contudo, consciente que a formulação de políticas e programas é resultado da disputa entre diferentes sujeitos, projetos políticos e perspectivas teóricas, bem como, que dificilmente são executados de acordo com seu desenho original e com as estratégias traçadas por seus formuladores, a política nacional para as mulheres necessita ainda ser objeto de estudo, pesquisa e avaliação.

$\mathrm{Na}$ impossibilidade de ser este texto uma avaliação da política, para concluir, detenho-me na questão: a política nacional e os planos de políticas para as mulheres são estratégias feministas visando incorporar-se à luta pela emancipação humana do domínio do capital? Pergunta que suscita controversas respostas. Tentarei fazer indicações de uma delas, embrionariamente em construção para este debate.

A implementação de políticas públicas são conquistas na luta pela instauração da igualdade jurídica, cidadania e democracia. Portanto, são conquistas no campo da emancipação política que nas sociedades capitalistas não elimina as desigualdades sociais e econômicas (TONET, 1844). Acrescento: e nas sociedades também patriarcais e racistas não elimina as desigualdades de gênero e étnico-raciais. declarou:

Marx (1843), em A Questão Judaica

Não há dúvida que a emancipação política representa um grande progresso. Embora não seja a última etapa da emancipação humana em geral, ela se caracteriza como a derradeira etapa da emancipação humana dentro do contexto do mundo atual. É óbvio que nos referimos à emancipação real, à emancipação prática.

Nesse sentido, a Política Nacional para as Mulheres é um grande passo (BRASIL, 2004a). Cito como uma das referências para tal afirmação a definição dos seus princípios orientadores: igualdade na diversidade, autonomia das mulheres, laicidade do Estado, universalidade, participação e solidariedade. Nos I e II PNPM estes princípios foram reafirmados e assim nomeados: igualdade e respeito à diversidade, equidade, autonomia das mulheres, laicidade do Estado, universalidade das políticas, justiça social, transparência dos atos públicos e da participação e controle social (BRASIL, 2004b, 2008).

- Igualdade e respeito à diversidade mulheres e homens são iguais em seus direitos e sobre esteprincípio se apóiam as políticas de Estado que se propõem a superar as desigualdades de gênero. A promoção da igualdade requer o respeito e atenção à diversidade cultural, étnica, racial, inserção social, de situação econômica e regional, assim como aos diferentes momentos da vida. Demanda o combate às desigualdades de toda sorte, por meio de políticas de ação afirmativa e consideração das experiências das mulheres na formulação, implementação, monitoramento e avaliação das políticas públicas.

- Eqüidade- o acesso de todas as pessoas aos direitos universais deve ser garantido com ações decaráter universal, mas também por ações específicas e afirmativas voltadas aos grupos historicamente discriminados. Tratar desigualmente os desiguais, buscando-se a justiça social, requer pleno reconhecimento das necessidades próprias dos diferentes grupos de mulheres.

- Autonomia das mulheres - deve ser assegurado às mulheres o poder de decisão sobre suas vidas e corpos, assim como as condições de influenciar os acontecimentos em sua comunidade e país, e de romper com o legado histórico, com os ciclos e espaços de dependência, exploração e subordinação que constrangem suas vidas no plano pessoal, econômico, político e social.

- Laicidade do Estado - as políticas públicas de Estado devem ser formuladas e implementadas demaneira independente de princípios religiosos, de forma a assegurar efetivamente os direitos consagrados na Constituição Federal e nos diversos instrumentos internacionais assinados e ratificados pelo Estado brasileiro, como medida de proteção aos direitos humanos das mulheres e meninas.

- Universalidade das políticas as políticas devem ser cumpridas na sua integralidade e garantir oacesso aos direitos sociais, políticos, econômicos, culturais e ambientais para todas as mulheres. O princípio da universalidade deve ser traduzido em políticas permanentes nas três 
esferas governamentais, caracterizadas pela indivisibilidade, integralidade e intersetorialidade dos direitos, e combinadas às políticas públicas de ações afirmativas, percebidas como transição necessária em busca da efetiva igualdade e eqüidade de gênero, raça e etnia.

- Justiça social - implica no reconhecimento da necessidade de redistribuição dos recursos e riquezas produzidas pela sociedade e na busca de superação da desigualdade social, que atinge de maneira significativa as mulheres.

- Transparência dos atos públicos deve-se garantir o respeito aos princípios da administração pública: legalidade, impessoalidade, moralidade, publicidade e eficiência, com transparência nos atos públicos e controle social.

- Participação e controle social - devem ser garantidos o debate e a participação das mulheres na formulação, implementação, avaliação e controle social das políticas públicas. (BRASIL, 2004a, p. 32-33; 2008, p. 2728).

O PNPM 2013-2015 também reafirma os princípios orientadores da Política Nacional para as Mulheres, mas altera a redação, exclui o principio da equidade e inclui um novo principio: a transversalidade. Ao contrário do texto da Política Nacional e dos Planos anteriores, não apresenta o entendimento de cada um dos princípios. É uma releitura do II PNPM, com a preocupação de ter viabilidade no Plano Plurianual Anual 20132015 e incorporando concepções e estratégias de implementação da política para as mulheres incorporadas ao longo de dez anos.

O PNPM 2013-2015 constitui-se em um elemento estrutural da configuração de um Estado democrático. Contribui para o fortalecimento e a institucionalização da Política Nacional para as Mulheres aprovada a partir de 2004, e referendada em 2007 e em 2011, pelas respectivas conferências. Como um plano nacional, reafirma os princípios orientadores da Política Nacional para as Mulheres:autonomia das mulheres em todas as dimensões da vida;- busca da igualdade efetiva entre mulherese homens, em todos os âmbitos;- respeito à diversidade e combate a todas asformas de discriminação;- caráter laico do Estado;- universalidade dos serviços e benefíciosofertados pelo Estado;participação ativa das mulheres em todasas fases das políticas públicas; e- transversalidade como princípio orientadorde todas as políticas públicas. (BRASIL, 2013b, p. 9-10)

Relembrando a histórica e presente condição de subordinação, dominação e exploração vividas pelas mulheres, agravadas segundo seu pertencimento de classe, cor, geração e outras expressões de diversidades, se faz necessário a criação e (re)afirmação de direitos, o fortalecimento da cidadania e da participação como sujeito político. A luta por políticas públicas, sua implementação e o controle social dessas políticas, contraditoriamente, podem ser também lócus de crítica, reação e resistência ao capitalismo, ao patriarcado, ao racismo.

A cidadania, a emancipação política das mulheres são exigências irrefutáveis, mas não bastam. É necessário ir além: inserir e fortalecer a luta feminista na perspectiva da transformação social, ter como horizonte a emancipação humana.

Recorro, então, aos estudos de Miranda (2015), ao tecer sua concepção de emancipação, alicerçada principalmente em Marx e Spinoza, e aporte de outros pensadores como Foucault, Boaventura Santos e Deleuze. Declara Miranda (2015, p. 36-37, grifo da autora):

Emancipação será aqui entendida nos termos de Santos (2008), como pluralidade de projetos coletivos articulados de modo não hierárquico por procedimentos de tradução. A sustentar essa pluralidade, defende o autor uma ética "a partir de baixo" que não implica relativismo plural, porque entende que não podemos abrir mão de uma ideia geral de transformação social.

A emancipação é antes de tudo, experimentação na transição, a se realizar em projetos que recuperem a força contida no presente, incorporando ações a paixões na composição de uma razão a ser reabilitada e vivida intensa e integralmente. Nessa direção, ela é, essencialmente, resistência (NEGRI, 2012). Mas mais adequado seria dizer experiências de resistência porque são processos que envolvem diferentes sujeitos, movimentos e lugares uma vez que, "como projeto político, a emancipação pressupõe uma diversidade de alternativas, com distintas vias de resistência e mobilização em resposta a múltiplas formas de domínio e opressão" (CARVALHO, 2008, p. 3).

Estamos convidadas/os a, parafraseando Thiago de Melo, a ter um jeito de caminhar novo. Assim, retorno a Matos (2014) que nos apresenta a proposta teórica no campo crítico-emancipatório das diferenças. Como Miranda, a autora nos tira da nossa zona de conforto para ousar conhecer, entender e lutar diante da realidade complexa do século XXI.

Afirma Matos (2014, p. 13, grifo da autora):

Esta outra proposta de enquadramento teórico-analítico se assenta numa crítica radical a todos os tipos de opressão, desigualdades e hierarquias. Este 
é o fio condutor do campo críticoemancipatório das diferenças, conforme já proposto por mim em 2012. Fundado em uma epistemologia crítica e da fronteira (Spivak,1988), aberta e na fronteira tensa e disputada entre as ciências e as lutas sociais, esse novo campo foi por mim concebido a partir, fundamentalmente de uma premissa inaugural: o compromisso normativo de se atribuir o justo reconhecimento político e acadêmico aos grupos subalternos, visando-se com isso fortalecer seus processos dinâmicos que visam a emancipação. Trata-se de uma "moldura teórica compreensiva, inclusiva, mais justa e mais fortemente democrática" (MATOS, 2012, p. 37).

Acrescenta a autora:

Assim, resumindo, afirmaria que este campo teria como seus principais pressupostos: o reforço das críticas de coloniais sobre o enraizamento da colonialidade do poder/saber/ser nas epistemologias de racionalidade ocidental hegemônica; o entendimento de que todo conhecimento é sempre parcial e depende do lugar da enunciação de quem fala, a diferenciação entre lugar epistêmico e lugar social (da perspectiva social de quem fala); a valorização da alteridade epistemológica, para que o campo seja capaz de produzir um tipo de conhecimento efetivamente emancipatório, desenvolvendo novas linguagens comuns e promovendo muito maior socialização do poder. Defendo, pois que é a partir das experiências de opressão e das perspectivas sociais de grupos subalternizados que poderão ser construídas as nossas mais recentes alternativas democráticas. Nesse sentido, a(s) diferença(s), desde que reivindicada(s), deve( $m$ ) funcionar como princípio para empoderar e emancipar, e não mais para oprimir. (MATOS, 2014, p. 20)

Diante de tantas indagações, polêmicas, discordâncias sobre como caminhar, não é possível escrever uma conclusão. Para o feminismo ainda se fazem necessárias muitas lutas e construção de estratégias na direção da emancipação feminina e humana.

\section{REFERÊNCIAS}

BRASIL. Presidência da República. Decreto $\mathrm{n}^{\circ}$ 8.030, de 20 de junho de 2013. Aprova a Estrutura Regimental e o Quadro Demonstrativo dos Cargos em Comissão da Secretaria de Políticas para as Mulheres da Presidência da República e remaneja cargos em comissão. Diário Oficial da União, Brasília, DF, 2013a.
Secretaria de Políticas para as

Mulheres. Plano Nacional de Políticas para as Mulheres 2013-2015. Brasília, DF, 2013b.

Anais da Conferência.

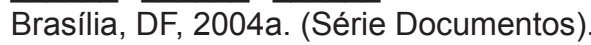

Plano Nacional de

Políticas para as Mulheres. Brasília, DF: 2004b.

II Plano Nacional de

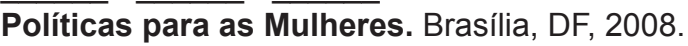

BUARQUE, C. Introdução ao Feminismo. In: VANIN, I. M. e GONÇALVES, T. (Organizadoras). Caderno de textos gênero e trabalho. Salvador: REDOR, 2006.

CARVALHO, M. E. P. de. Oficina Epistemologia Feminista: notas. In: $17^{\circ}$ ENCONTRO NCIONAL DA REDE FEMINISTA NORTE E NORDESTE DE ESTUDOS E PESQUISAS SOBRE A MULHER E RELAÇÕES DE GÊNERO, 17., 2012, João Pessoa. Anais... João Pessoa: NIPAM/UFPB, 2012.

FERREIRA, M. M. As "caetanas" vão à luta: a trajetória do Movimento Feminista no Maranhão face às políticas públicas. 1999. 258 f. Dissertação (Mestrado em Políticas Públicas) - Programa de Pós-Graduação em Políticas Públicas, Universidade Federal do Maranhão, São Luís, 1999.

MARX, K. A Questão Judaica. [S. I.: s. n.], 1843. Não paginado. Disponível em:<https://www.marxists.org/ portugues/marx/1843/questaojudaica.htm>. Acesso em: 19 jun. 2015.

MATOS, M. A Quarta onda feminista e o Campo crítico-emancipatório das diferenças no Brasil: entre a destradicionalização social e o neoconservadorismo político. In: ENCONTRO ANUAL DA ANPOCS, 38., 2014, Caxambu. Anais... Caxambu: ANPOCS, 2014.

CYPRIANO, B. Críticas feministas, epistemologia e as teorias da justiça social: em busca de uma teoria crítico-emancipatória de gênero. In: ENCONTRO ANUAL DA ANPOCS, 32., 2008, Caxambu. Anais... Caxambu: ANPOCS, 2008.

MÉSZÁROS, I. Para além do capital: rumo a uma teoria da transição. São Paulo: Boitempo Editorial; Campinas, SP: Editora da UNICAMP, 2002.

MIRANDA, M. L. B. (Re)inventar a resistência emancipatória: ética e política dos afetos no serviço social. 2015. Projeto de Tese (Doutorado em Políticas Públicas) - Programa de Pós-Graduação em Políticas Públicas, Universidade Federal do Maranhão, São Luís, 2015. 
NARVAZ, M. G.; KOLLER, S. H. Metodologias feministas e estudos de gênero: articulando pesquisa, clínica e política. Psicologia em Estudo, Maringá, v. 11, n. 3, p. 647-654, set./dez. 2006. Disponível em:<http://www.scielo.br/scielo.php?script=sci arttext\&pid=S1413-73722006000300021\&Ing=enee \&nrm=iso\&tlng=enee>. Acesso em: 4 maio 2008.

PINTO, C. R. J. Uma história do feminismo no Brasil. São Paulo: Ed. Perseu Abramo, 2003.

SAFFIOTI, H. I. B. Feminismos e seus efeitos no Brasil. In: SADER, E. (Org.). Movimentos sociais na transição democrática. São Paulo: Cortez, 1987. p.105-158.

SANTOS, B. de S. A construção multicultural da igualdade e da diferença. Oficina do CES, Coimbra, n. 135, jan. 1999 .

SARDENBERG, C.; COSTA, A. A. "Introdução". In: (Orgs.). Feminismo, ciência e tecnologia. Salvador: REDOR/NEIM-FFCH/UFBA, 2002.

SILVA, M. O. S. e. Avaliação de políticas e programas sociais: uma reflexão sobre o conteúdo teórico e metodológico da pesquisa avaliativa. In:

(Coord.). Pesquisa Avaliativa: aspectos teóricometodológicos. São Paulo: Veras; São Luís: GAEPP, 2008.

TONET, I. A propósito de "Glosas Críticas". In: MARX, K. Glosas Críticas Marginais ao artigo "O Rei da Prússia e a Reforma Social": de um prussiano. São Paulo: Ed. Expressão Popular, 1844. Disponível em:<https://www.marxists.org/portugues/ marx/1844/08/a_proposito_de_glosas_criticas.pdf $>$. Acesso em: 19 jun. 2015.

WALLERSTEIN, I. ¿Qué significa hoy ser unmovimientoanti-sistémico? OSAL: Observatorio Social de América Latina, Buenos Aires, ano 3, n. 9, ene. 2003. Disponible en:<http://bibliotecavirtual. clacso.org.ar/ar/libros/osal/osal9/wallerstein.pdf>. Acceso em: 20 jun. 2015.

\section{NOTAS}

1 Considerações sobre a proposta teórica no campo crítico-emancipatório das diferenças serão realizadas no item 3

2 Matos (2014) cita o exemplo da Marcha Mundial das Mulheres (MMM), um movimento/rede de resistência contra a pobreza e a violência, nascido em 1999 no Canadá. A luta contra pobreza é mantida e ampliada "[...] para a luta por 'um outro mundo' (designada de 'altermundialismo'), e por novos direitos humanos, em que sejam superados os legados históricos do patriarcalismo e do capitalismo, onde são os movimentos de mulheres no campo/rurais e também os feminismos e movimentos de mulheres urbanas (moradia/habitação, trabalhadoras e operárias etc.) que têm resignificado as lutas por mais justiça." (MATOS, 2014, p. 10)

3 Desde março de 2010, tornou-se "órgão essencial" da Presidência da República, com a mesma estrutura (recursos humanos e financeiros) dos Ministérios com a denominação de Secretaria de Políticas para as Mulheres.

Lourdes de Maria Leitão Nunes Rocha

Assistente Social

Doutora em Políticas Públicas pela Universidade Federal do Maranhão (UFMA)

Professora Aposentada do Programa de Pós-Graduação em Políticas Públicas da UFMA

E-mail: lourdesleitaorocha@yahoo.com.br

Universidade Federal do Maranhão - UFMA

Cidade Universitária Dom Delgado

Av. dos Portugueses, n. 1966, Bacanga, São Luís/MA CEP: $65085-580$ 